\section{Factors Affecting Customer Experience of E-Commerce in Pakistan}

\author{
Waqas Zaki ${ }^{1}$, Areej Tayyab ${ }^{2}$,Aeman Hassan ${ }^{3}$
}

The Educational Paradigms 2019, Vol. 01(02) 76-79 (C) Authors ISSN (Print): 2709-202X ISSN (Online): 2709-2038 DOI: $10.47609 / 0102052019$

\begin{abstract}
The study is regarding analyzing the factors affecting customer experience of e-commerce in Pakistan through the quality of the product, safety of application, delivery guarantee, and offers. Using the purposive sampling technique total of 180 questionnaires were collected from the people having the experience of online shopping in Lahore, Pakistan. The study shows the factors and their roles tow ards raising the customer experience of e-commerce. This study's results reveal that the perception of customers is that the quality of the product, application safety, offers, and the delivery guarantee affects the customer comfort level and satisfaction level. The study results also reveal that the lower delivery charges, guaranteed delivery, and no safety risks motivate the customers to go for online shopping. It concluded that if the marketers concentrate on the factors like product quality, security issues, delivery risks, and the financial risks, it increases the customers. Limited literature has been documented in Pakistan, particularly regarding customer perception for online shopping because there are too many factors that affect the purchase intention. The results of the study might be beneficial for the online marketers/ companies with online stores/ e-commerce stores.
\end{abstract}

Keywords: E-commerce, Offers, Delivery guarantee, Customer experience, Application safety, Product quality.

The number of online shoppers is increasing worldwide because they feel that shopping online is more comfortable than traditional shopping. Customers can purchase goods straightforwardly from the vendor through the internet. It is a type of e-commerce. Customer buys mostly founded on the internet form such as photographs, pictures, quality data, and product videos, rather than on the genuine experience (Kolesar, and Wayne Galbraith, 2000). Online shopping resembles shopping through a paper catalog because both include mail conveyance of the purchases, and in the two cases, clients cannot contact or smell the goods (Lohse, \& Spiller, 1998). When making purchases on the internet, customers can view photos and images and find company products and services. And do real time shopping according to the specifications, features, and pricing on the product.

Online shopping has gained popularity among the Pakistani youth with the quickest development of the internet. The more youth rely on the web because they are used to using the internet in all things. The young generation is increasingly keen on pursuing everything online (El Khatib, \& Khan, 2017). Although the Pakistani market is little, easily accessible to the web allows young people to feel that shopping online is easy and straightforward, so they believe that shopping online is excellent. Shopping on the internet has led to higher client turnout because it is easier to shop being at home at a generally lower value contrasted with conventional shopping (Al-Jahwari, Khan, Al Kalbani, \& Al Khansouri, 2018). When buyers make purchases online, they don't need to rush to buy a particular item in a specific store, and making purchases is easy. It looks like a mall where you can purchase several brands/ items in a single spot. This innovation helps users react quicker.

Numerous online shopping sites are well-known to young Pakistanis viz. Daraz, Lootlo, Kaymu, Yayvo, elo, khazanay,
Aliexpress, etc. All these sites to increase customer satisfaction and retain their users. These brands are mostly focused on Pakistani youth because they either import products directly or tend to buy imported goods. Therefore, online retailers are trying not only to attract a lot of Pakistani consumers, but also to provide services and build up the Pakistani youth through online exposure. Although the four measures of service quality of e-commerce play an important role in customer experience, the components that strengthen the consumer experience on the mentality of Pakistanis need to be analyzed and linked to the quality of the product, safety of application, delivery guarantee, and the offers. Online shoppers focus on these factors; however, the purchasers still have the following inquiries:

1. How reliable is the dissemination of information through these online sites?

2. How accurate are transaction systems and security dimensions?

3. What is the guarantee that their personal information will not be hacked?

4. What is the assurance for delivery of the ordered goods without interruption?

The customers have faced some bitter experiences, so it affects the comfort level and satisfaction level of customers. Therefore, the study should identify the primary factors and expectations that online customers of Pakistan feel. This study helps to analyze and summarize factors to improve the customer experience by meeting the customer expectations.

\section{Literature Review}

Molla, and Heeks, (2007) Through the improved worth chain, increment in productivity, and proficiency of the administrations, the internet retailing benefits the organizations. (Khan, Hatami, Sasidharan, \& Al-Roshdi, 2017) claimed that the simple way to

${ }^{123}$ UCP Business School, Faculty of management studies, UCP, Pakistan. Corresponding author: zaki@ ucp.edu.pk 
impact clients is through web-based selling and purchasing. (Zatalini, \& Pamungkas, 2017) Pointed out that the protection of client data and securities are the variables that prompt client steadfastness, and the fruitful usage of web-based purchasing is the speed of administration. The costumers' fulfillment, the significant factor is security.

The electronic stores have a significant degree of user security and certainty of every item, which drives the purchasers to purchase the item with less need to indeed include in its acquiring and more straightforward purchasing product. (Vehovar, 2003) Showed that the security concerns go about as hindrances against web-based retailing and legitimately influence consumer loyalty. The application security chance factor may influence the choice of the purchaser encounters to arrange the item online. Javadi, Dolatabadi, Nourbakhsh, Poursaeedi, and Asadollahi, (2012) stated that the money related hazard and the non-conveyance chance influence online client experience. Along these lines, the online retailers should make the sites more secure and guarantee brief conveyance. The budgetary hazard and security chance imply that the purchasers can misfortune their master cards or any misfortune where cash is included. The monetary and security risk has a critical effect on the choice of who shop on the web. Likewise, it carries dangers on purchasers, which negatively impacts them. Purchasers feel stress with Visa using to hack individual data along these lines to save themselves shopper favor options for installment; for example, in Pakistan, 97\% of individuals use money down strategy for web-based shopping. PTA. PTA (Pakistan Telecommunication Authority) Annual report 2019. The budgetary hazard is because of the absence of trust of purchasers on the web-based shopping encounters. Oxley and Yeung (2001) affirmed that internet shopping is the simple access to the enormous measure of data at a decreased expense. Each item that put online has more data with reduced expenses rather than the physical markets. (AlGhamdi, Nguyen, Nguyen, \& Drew, 2012) guaranteed that the government acts as a reliable and secure online installment. Alternative, web-based business support, solid ICT framework, and instructive web-based business mindfulness programs in the nation that empower the organizations in internet retailing, which help to assemble trust in buyers' encounters. (Eid, 2011) asserted, if the client is guaranteed the item quality and quality data, the trust and consumer loyalty could be upgraded. (Khan, Al-Balushi, Algaithi, \& Al-shihi, 2017) ensured that the data is the factor that profoundly initiates the client experience fulfillment and trust. (Tsiotsou, 2006) asserted that immediate effect on the general fulfillment of procurement aims by apparent item quality. The offers, limits, and advancements pull in the clients for internet shopping. At the point when online stores set advancements or limits for their clients, they are boosting up their clients for shopping and holding their clients. The clients who have budgetary issues purchasing the items got an opportunity to buy those items at sensible costs. That likewise prompts improve the client's web-based shopping experiences. The item quality is the primary need of the purchaser. Clients get a kick out of the chance to visit online web stores for different and high-caliber items. On the off chance that the clients get the item in that quality from web-based shopping, it is reasonable to manufacture trust in the shopper for utilizing internet shopping. (Lin, Wu, \& Chang, 2010) recognized that the most significant components influencing the web purchaser experience fulfillment are conveyance quality, item quality, and administration quality. (Alam, \& Yasin, 2010) expressed that the four key elements affecting web-based shopping shopper web-based shopping experience fulfillment. The item quality, offers, item assortment, and conveyance exhibitions are the online stores assumes basic job to fulfill their shoppers. With the help of internet shopping, customers get their attractive items at home by safe conveyance administrations. After ultimately experiencing the above writing audit, the survey was set up under the factors recognized, and the information gathered from the respondents.

\section{Quality of a Product}

The nature of an item effectively affected the shopper's internet shopping encounters. Online stores have to fulfill buyers by giving them the perfect nature of an issue that they are normal from online stores. (Eid, 2011) proclaimed that internet shopping clients experience fulfillment and trust could be kept up by giving them high caliber and more extensive data. Online stores give their client a superior quality item with decreased rates. The client gets the comprehensive and higher data of an item, which positively affected clients purchasing choice. The online stores have an item hazard because the conventional shopping technique progressively fulfills the clients; they can get the item before them. On the off chance that online stores are neglected to give their client the ideal item, it causes a decrease in the client's unwariness.

\section{Application Safety}

The administrations of web-based shopping are joined by security dangers, such as wholesale fraud and misrepresentation (Tsiakis, 2012). The hazard relates to the client's Master card data is hacked, and it causes the loss of cash. (Pavlić, Jadrić, \& Ćukušić, 2012) as a result of their research, the media's new user is worried about data manipulation, unauthorized data access, and insecurity by unwanted tracking of services by the third party. In online shopping, the settlement between the security and comfort can be seen in secret words to get to frameworks (Lee, Rao, Nass, Forssell, \& John, 2012). Because of the security risk, customers prefer cash on delivery methods, and many avoid online shopping. The online stores should make a secure method to retain their customers.

\section{Delivery Guarantee}

The conveyance chance, which is ever seen by the client, is ontime delivery (OTD) and delivery without harm. Deferred conveyance negatively affects fulfillment. Online buys can't utilize or devour the item by clients quickly, and they should hang tight for item conveyance. (Ryan, \& Valverde, 2005) the delivery chance included when the client didn't get their item on the schedule, it set aside an extended effort to convey, or the item is harmed. Chang, Wang, \& Wang, (2012) also stated that delay of delivery caused negative results and customer dissatisfaction.

\section{The Offers}

The offers attract the customers towards the online shopping. The sales offers can help to create information about new products. It is the primary mechanism that uses to interact and build a more reliable connection with their customer. People prefer buying the 
products on discount. To satisfy the customers' online shopping experiences, stores offer discounts. To boost the customers, customers who are in stressful situations, or have any financial problem who cannot buy the products; due to these promotions, they can buy the products.

\section{Research Methodology}

This study is carried out by a self-administered questionnaire. The measuring instrument is adopted. This study uses a simple random sampling technique. The consumers of online shopping are the population of this study.

One hundred ninety questionnaires were collected from the people having the experience of online shopping in Lahore, Pakistan. In this study, variables are obtained through the above review of literature application safety, quality of a product, offers, and delivery guarantee. With the help of questionnaires, we analyze the factors that affect the consumer experience of online shopping.

Data Analysis

Table 1: Reliability Statistics (Product Quality)

\begin{tabular}{lc}
\hline Cronbach's Alpha & N of Items \\
\hline .604 & 5 \\
\hline
\end{tabular}

The observed p-value is less than 0.05 . The strength of association is moderate in the variable of product quality.

Table 2: Reliability Statistics (Application Safety)

\begin{tabular}{lc}
\hline Cronbach's Alpha & N of Items \\
\hline 630 & 5 \\
\hline
\end{tabular}

The observed p-value is less than 0.05 . The strength of association is moderate in the variable of application safety.

Table 3: Reliability Statistics (Delivery Guarantee)

\begin{tabular}{lc}
\hline Cronbach's Alpha & N of Items \\
\hline .612 & 5 \\
\hline
\end{tabular}

The observed p-value is less than 0.05 . The strength of association is moderate in the variable of delivery guarantee.

Table 4: Reliability Statistics (Offers)

\begin{tabular}{lc}
\hline Cronbach's Alpha & N of Items \\
\hline 653 & 5 \\
\hline
\end{tabular}

The observed p-value is less than 0.05 . The strength of association is moderate in the variable of offers.

Table 5: Reliability Statistics (Customer Experience)

\begin{tabular}{lc}
\hline Cronbach's Alpha & N of Items \\
\hline 707 & 5 \\
\hline
\end{tabular}

The observed p-value is less than 0.05. The strength of association is good in the variable of customer experience through online shopping.

Table 6: Model Summary

\begin{tabular}{llllll}
\hline $\mathbf{R}$ & $\begin{array}{l}\mathbf{R} \text { Square } \\
\text { Change }\end{array}$ & $\begin{array}{l}\text { Adjusted } \\
\text { Square }\end{array}$ & $\begin{array}{l}\text { R } \\
\text { F Change }\end{array}$ & $\begin{array}{l}\text { Sig. } \\
\text { Change }\end{array}$ \\
\hline 1 & $.743^{\text {a }}$ & .553 & .543 & 57.126 & .000 \\
\hline${ }^{a}$ Predictors: (Constant), Offers, Application Safety, Product Quality, Delivery Guarantee.
\end{tabular}

It is confirmed that the entire model has a significant relationship which reveal to us that customer experience is anticipated through the product quality, application safety, delivery guarantee and the offers.

Table 7: Coefficients of variable

\begin{tabular}{lll}
\hline Variable & Beta & Sign. \\
\hline Product Quality & 0.192 & 0.008 \\
Application Safety & 0.184 & 0.008 \\
Delivery Guarantee & 0.236 & 0.002 \\
Offers & 0.365 & 0.000 \\
\hline
\end{tabular}

The variable product quality has beta 0.192 , which is significant at 0.008 . It shows that product quality has a significant relationship, contributing to the customer experience through online shopping. The variable application safety has beta 0.184 , which is significant at 0.008. It shows that application safety has a significant relationship, and it is contributing to the customer experience through online shopping.

The variable delivery guarantee has beta 0.236 , which is significant at 0.002 . It shows that a delivery guarantee has a significant relationship, and it is contributing to the customer experience through online shopping. The variable offers have beta 0.365 , which is significant at 0.000 . It shows that the offers have a significant relationship, and it is contributing to the customer experience through online shopping.

From the above table:7, it is observed that the product quality, application safety, delivery guarantee, and the offers influence the customer experience and affect online shopping customer experience.

\section{Conclusion and Recommendations}

The customers' online shopping experiences determined that Daraz is the most preferred website for the buyers. The product quality and service guarantee influence the online shopping customer's satisfaction and comfort. The customers get more comprehensive information about their desired product, according to customers' experience, that the application safety is in the secured payment method. The website of the Daraz is userfriendly, and it has the security procedures of returning products and cashback facility. The customers of online shopping are felt secured by sharing their personal information with the website. The customers of the Daraz are satisfied by the delivery process when they get their product safe without any damage. The customers get their package on time, and the quality of a package was assured. The customers of the Daraz know that they get their product at a reasonable cost without compromising the quality. Daraz gave great offers to the traditional markets to its customers. Daraz is the platform for fast and secure shopping. Daraz attracts the customers to shop online again and again.

The users' perceptions confirm that the Product Quality, Application Safety, Delivery Guarantee, and the Offers directly impact online customer experiences. Thus, it is recommended that the online shoppers in Pakistan should take care of the following: The quality of a product and verity of a product should not compromise by the online shoppers. The website should be easy to access for the customers because it directly affects the customers. The online markets should perform their duties according to the customer's relationship management (CRM). They should take no delay in attending or solve the query, problems related to the goods they ordered or feedback, etc. Delivering process should be efficient, by delivering the products on time without any damage. The application should be userfriendly customers should not feel insecure by sharing their personal information, and the online shoppers should maintain secrecy. The new offers attract the online buyers of Pakistan, so the online shoppers should update them regularly. 


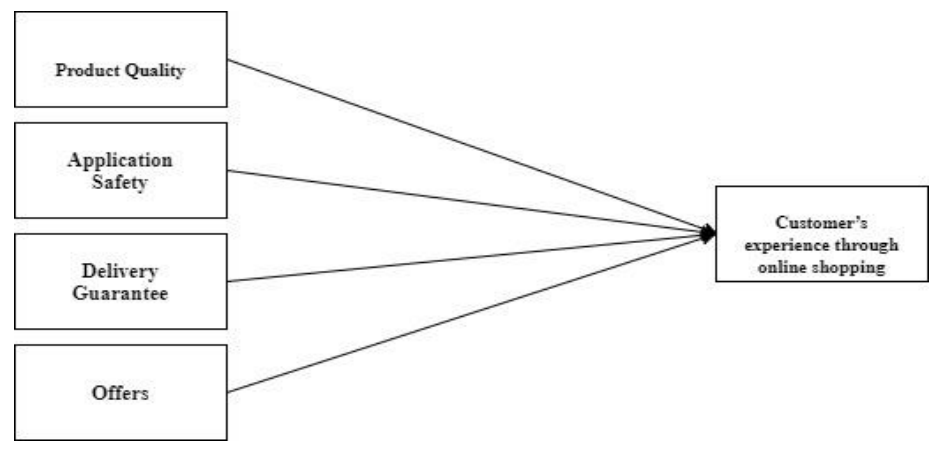

Figure 1: Conceptual Framework

According to this model, it is evident that the four factors viz. Product Quality, Application Safety, Delivery Guarantee, and offers directly impact Customer' experience who are online buyers. The customer's online shopping experience can be improved through the reasonable information of a product, by giving the best quality of a product. If the online shoppers solve the problems related to their ordered product, it increases the customer's satisfaction. By providing the best delivery services, they can build the trust between their customers. Thus, the model illustrates the factors; the online shoppers should concentrate on improving the consumer online shopping experiences, loyalty, and Best-purchase. It offers the element that needs more consideration regarding increment the Pakistani demographic.

\section{References}

Alam, S.S. \&Yasin, N.M. (2010). An Investigation into the antecedents of customer satisfaction of online shopping. Journal of Marketing Development and Competitiveness, 5(1), 71-78.

AlGhamdi, R., Nguyen, A., Nguyen, J. \& Drew, S. (2012). Factors influencing e-commerce adoption by retailers in Saudi Arabia: A quantitative analysis. International Journal of Electronic Commerce Studies, 3(1), 83-100.

Al-Jahwari, N. S., Khan, F. R., Al Kalbani, G. K., \& Al Khansouri, S. (2018). Factors influencing customer satisfaction of online shopping in Oman: Youth perspective. Humanities \& Social Science Reviews, 6(2), 64-73. eISSN, 2395-7654.

Chang and Wang Chang, D.S. and Wang, T.H. . (2012). Consumer preferences for service recovery options after delivery delay with shopping online. Social Behavior and Personality, 40(6), 1033-1044.

Eid, M. I. (2011). Determinants of e-commerce customer satisfaction, trust, and loyalty in Saudi Arabia. Journal of Electronic Commerce Research, 12(1), 78-93.

El Khatib, M. \& Khan, F.R. (2017). Implications of social media technology in interpersonal skills and academic performances. International Journal of Management, Innovation and Entrepreneurial Research, 3(2), 99-110.

Jahankhani, H., Georgiadis, C. K., Pimenidis, E., Bashroush, R., \& Al-Nemrat, A. (Eds.). (2012). Global Security, Safety, and Sustainability: 7th International and 4th e-Democracy Joint Conferences, ICGS3/e-Democracy 2011, Thessaloniki, Greece, August 24-26, 2011, Revised Selected Papers (Vol. 99). Springer.

Javadi, M.H.M., Dolatabadi, H.R., Nourbakhsh, M., Poursaeedi, A. and Asadollahi, A. R. (2012). An analysis of factors affecting on online shopping behavior of consumers. International Journal of Marketing Studies, 4(5), 81-98.

Khan, F.R., Hatami, Y.J., Sasidharan, A. \& Al-Roshdi, S.A.A. (2017). Investigative study of preferred social media marketing in safeer mall, Sohar, Oman. Humanities \& Social Science Reviews, 5(1), 53-63.

Khan, F.R., Al-Balushi, H.Y., Algaithi, A.D. \& Al-shihi, A.A. (2017). Impact of social media on customer satisfaction: Bank Muscat - A case study. Ahead International Journal of Recent Research Review, 1(11), 154-164.

Kolesar, M. and Wayne Galbraith, R. (2000). A servicesmarketing perspective on e-retailing: implications for e-retailers and directions for further research. Internet Research, 10(5), 424-438.

Lee, J. R., Rao, S., Nass, C., Forssell, K., \& John, J. M. . (2012). When do online shoppers appreciate security enhancement efforts? Effects of financial risk and security level on evaluations of customer. International Journal of HumanComputer Studies, 70(5), 364-376.

Lin, C., Wu, H. \& Chang, Y. (2010). The Critical factors impact on online customer satisfaction. Procedia Computer Science, 3(1), 276-281.

Lohse, G.L. and Spiller, P. (1998). Electronic shopping. Communications of ACM, 41(7), 81-87.

Molla, A. \& Heeks, R. (2007). Exploring e-commerce benefits for businesses in a developing country. The Information Society, 23(2), 95-108.

Oxley, J.E. \& Yeung, B. (2001). E-commerce readiness: Institutional environment and international competitiveness. Journal of International Business Studies, 32(4), 705-723.

Pavlić, D., Jadrić, M., \& Ćukušić, M. (2012). Influence of various factors on the intended use of mobile marketing services. WSEAS Transactions on Information Science and Applications, 9(6), 179-188.

Ryan, G. and Valverde, M. (2005). Waiting for service on the internet: Defining the phenomenon and identifying the situations. Internet Research, 15(2), 220-240.

Tsiotsou, R. (2006). The role of perceived product quality and overall satisfaction on purchase intentions. International Journal of Consumer Studies, 30(2), 207-217.

Vehovar, V. (2003). Security concern and online shopping. An International Study of the Credibility of the Consumer Information on the Internet Submitted to the Faculty of Social Sciences, University of Ljubljana, 1-36.

Zatalini, M.A. \& Pamungkas, T.N. (2017). Exploring the success factors of e-crm implementation on B2C e-commerce: Satisfaction and Loyalty a Conceptual Framework. Jurnal Ekonomi Bisnis, 22(2), 94-106. 